\title{
William Thomson: President-elect of the Society for Social Choice and Welfare 2002-2003, President 2004-2005
}

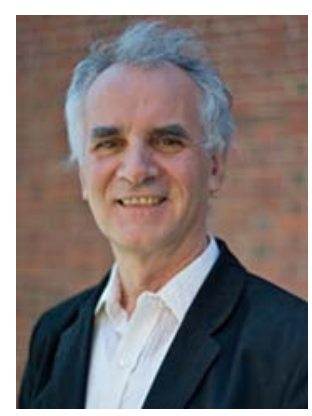

Born in 1949, William Thomson graduated from Ecole Polytechnique in 1972, and earned a Ph.D in Economics from Stanford University in 1976. He taught at the University of Minnesota, Harvard University, and the University of Rochester, where he is currently the Elmer B. Milliman Professor of Economics. He has held visiting positions at Harvard University, the University of Caen, the University of Cergy-Pointoise, and the Paris School of Economics. He has served on the board of Editors of Economics Letters, Social Choice and Welfare, Games and Economic Behavior, The Review of Economic Design, Mathematical Social Sciences, Economic Theory, The Journal of Economic Theory, The Theory and Decision Library, and the International Journal of Game Theory, of which he was the Editorin-Chief from 2003 to 2008.

His main contributions have been to the theory of cooperative games, mechanism design, and the axiomatics of resource allocation. His early study mainly concerned Nash's abstract model of bargaining. More recently, he has investigated a variety of resource allocation problems. They include dividing goods in classical environments, sharing the cost of public goods, assigning indivisible goods, allocating surpluses and deficits, partitioning a non-homogeneous continuum, and adjudicating conflicting claims. In addition to punctual notions of fairness, he has examined the implications of relational requirements pertaining to variations in resources, endowments, claims, and preferences. Models in which population may vary, and properties of population monotonicity and consistency have been the central focus. The manipulability of allocation rules and their implementability has been another. He is the author of several books.

He was elected Fellow of the Econometric Society in 1990, and he is the recipient of the 2001 Prize for Excellence in Graduate Teaching awarded annually by the University of Rochester. 